\title{
In situ X-ray Diffraction Investigation of Hydrogen Storage Alloys During Charge and Discharge
}

\author{
Waldemir J. Paschoalino ${ }^{\mathrm{a}, \mathrm{b}}$, Stephen J. Thompson ${ }^{\mathrm{b}}$, David Inwood ${ }^{\mathrm{b}}$, Claire Murray ${ }^{\mathrm{c}}$, Chiu C. Tang ${ }^{\mathrm{c}}$, \\ Edson A. Ticianellia, ${ }^{\star}$ and Andrea E. Russell .
}

\begin{abstract}
Metal hydride electrodes have shown to be useful both in secondary batteries, e.g. the $\mathrm{Ni} /$ metal hydride system, and more recently in fuel cells, especially for direct borohydride fuel cells. This work provides in situ X-ray diffraction (XRD) results aiming at characterizing the phase transitions of the $\mathrm{LaNi}_{4.7} \mathrm{Sn}_{0.2} \mathrm{Cu}_{0.1}$ metal hydride alloy with and without $\mathrm{Pt}$ in the particle surface when charged electrochemically and chemically by exposition to a borohydride solution. Results have shown that the method of alloy charging leads to different phase predominance and different site occupancies, but both methods lead to almost the same discharge capacity. In the electrolysis process, $\gamma-\beta$ phase transitions are predominant during the charge/discharge, while in the chemical charging by exposure to a borohydride solution the $\alpha-\gamma$ phase transition is more important, indicating occurrence of smaller localized stress in the alloy, with benefit on the material lifetime. Essentially the same phenomena were observed for the alloy with $\mathrm{Pt}$, either with respect to the alloy structure and the electrochemical characteristics.
\end{abstract}

\section{Introduction}

Metal hydride electrodes have shown to be useful both in secondary batteries, e.g. the $\mathrm{Ni} /$ metal hydride system, and more recently in fuel cells, especially for direct borohydride fuel cells..$^{[1,2]}$ The charge and discharge processes of the metal hydride alloy are important in both of these systems. In the battery application, the extent of charging determines the discharge capacity, and the rate of diffusion of the hydride species within the structure of the alloy contributes to the limiting rate of charge or discharge. For fuel cell applications, the formation of the hydride phase may affect both the catalytic activity and the structural stability of the electrode. ${ }^{[3,4]}$

The most common Ni/metal hydride battery anode uses an $\mathrm{AB}_{5^{-}}$ type material, which is an intermetallic alloy where the A element is usually $\mathrm{La}$ or $\mathrm{Mm}$ (misch metal, which a natural mixture of metals comprised of $\mathrm{Ce}, \mathrm{La}, \mathrm{Nd}$ and $\mathrm{Pr}$ ). The B element may be

[a] W. J. Paschoalino and Prof. E. A. Ticianelli Department of Physico-Chemistry Instituto de Química de São Carlos - USP CP 780, São Carlos, SP, Brazil E-mail: edsont@iqsc.usp.br

[b] Dr. S. J. Thompson, D. Inwood and Prof. A. E. Russell Chemistry Department University of Southampton Highfield Southampton, SO17 1BJ, UK, 442380593306

[C] Dr. C. Murray and Dr. C. C. Tang Diamond Light Source

Harwell Science and Innovation Campus Didcot, Oxfordshire OX11 ODE, United Kingdom any or a combination of transition metals. The structure of this type of alloy generally follows that of $\mathrm{LaNi}_{5}$, which crystallizes in the $\mathrm{CaCu}_{5}$-type structure (space group $\mathrm{P} 6 / \mathrm{mmm} ; 1 \mathrm{La}$ in $1 \mathrm{a}: 0,0$, $0 ; 2 \mathrm{Ni} 1$ in $2 c: 1 / 3,2 / 3,0 ; 3 \mathrm{Ni2}$ in $3 g ; 1 / 2,0,1 / 2$ ).

Replacement of $\mathrm{La}$ and $\mathrm{Ni}$ by different $\mathrm{A}$ and $\mathrm{B}$ elements can dramatically improve the cycle life of the alloys and reduce problems of hysteresis, peak broadening and intrinsic degradation. ${ }^{[5]}$ These problems appear, because the hydriding and dehydriding processes lead to an increase or decrease of the lattice constant of the crystal structure, respectively. Such changes may cause particle collapse leading to the formation of segregated lanthanum phases, which diminishes the electrical conductivity and increases the surface area leading to increased alloy corrosion. ${ }^{6]}$ Partial substitutions of the $A$ and $B$ components can also lead to improvement of the maximum discharge capacity of the alloys. For example, the substitution of molybdenum to form $\mathrm{La}_{0.35} \mathrm{Ce}_{0.65} \mathrm{Ni}_{3.54} \mathrm{Co}_{0.80-x} \mathrm{Mn}_{0.35} \mathrm{Al}_{0.32} \mathrm{Mo}_{\mathrm{x}}(\mathrm{x}=0.00,0.10,0.15,0.20$, 0.25 ) was investigated and it was observed that the composition where $x=0.25$ presented the highest discharge capacity and faster electrochemical kinetics compared to the other compositions. $^{[7]}$ Recently, catalytic electrodes consisting of $\mathrm{MmNi}_{0.58} \mathrm{Co}_{0.07} \mathrm{Mn}_{0.04} \mathrm{Al}_{0.02}$ ( $\mathrm{AB}_{5}$-type alloy) and multi-walled carbon nanotubes (MWNTs) were investigated for $\mathrm{NaBH}_{4}$ electrooxidation by cyclic voltammetry. It is found that the electrode performance is significantly affected by the content of MWNTs and the optimized content of MWNTs is found to be 2 wt.\%. This was attributed to MWNTs, which acts as a hydrogen adsorbent to diminish hydrogen release. ${ }^{[8]}$

In situ X-ray powder diffraction (XRD), such as used in the investigation reported herein, enables the structure of the metal hydride alloy to be monitored during the processes of hydrogen absorption and desorption. Previously reported in situ XRD studies of the mechanisms of phase/structural transformations during hydride formation, decomposition, and the kinetics of the absorption/desorption processes in "fast" intermetallic hydrides such as $\mathrm{LaNi}_{5} \sim \mathrm{H}_{6}$ have shown the contributions of three hydride phases and their interconversion $(\alpha \rightarrow \gamma \rightarrow \beta) \cdot{ }^{[9,10]}$ In situ XRD results obtained during the hydriding-dehydriding process of a $\mathrm{LaNi}_{4.75} \mathrm{Sn}_{0.25}$ alloy electrode showed that a lattice strain occurs in the hydride phase during the hydriding process. ${ }^{[11]} \mathrm{A}$ study of the activation of $\mathrm{LaNi}_{5}$ and $\mathrm{LaNi}_{4.75} \mathrm{Al}_{0.25}$ found changes in the crystallite size and evidence of lattice strain during this process. [12] For $\mathrm{LaNi}_{4} \mathrm{Co}$ it was observed that the presence of $\mathrm{Co}$ in the composition of the alloy generates less internal stress and leads to a higher discharge capacity compared to $\mathrm{LaNi}_{5}{ }^{\left[{ }^{[}\right]}$

Several metal alloy hydrides have been studied in our group as electrocatalysts for the oxidation of borohydride ions in alkaline media. The electrochemical data suggest that alloy hydriding occurs simultaneously with the borohydride oxidation. We 
showed that $\mathrm{LaNi}_{4.7} \mathrm{Sn}_{0.2} \mathrm{Cu}_{0.1}$ and $\mathrm{LaNi}_{4.7} \mathrm{Sn}_{0.2} \mathrm{Cu}_{0.1}$ - Pt were able to charge when exposed to the borohydride solution [13] and that the hydrolysis process of borohydride ions on $\mathrm{LaNi}_{4.7} \mathrm{Sn}_{0.2} \mathrm{Cu}_{0.1}$ was not significant. The study reported in this work provides in situ XRD results aiming at characterizing the phase transitions of the alloys when the electrodes are exposed to borohydride solution. Results obtained for the formation of the hydride phase via electrolysis are compared to those obtained for the spontaneous formation of the hydride upon contact with the borohydride solution.

\section{Results and Discussion}

Fig. 1 shows the electrode potential vs. discharge capacity curves obtained during the electrochemical discharging process $\left(i_{\text {discharge }}\right.$ $=1.0 \mathrm{~mA}$ ), for the electrodes charged either electrochemically applying a cathodic current $(-1.0 \mathrm{~mA})$ or chemically by exposure to $\mathrm{NaBH}_{4} 10^{-2} \mathrm{~mol} \mathrm{~L}^{-1}$ for two hours in the in situ XRD flow cell. During both of these procedures, XRD measurements were carried out every 20 seconds, with the aim of mapping the structural changes occurring during the processes of charge and discharge either by water electrolysis and by exposure to borohydride ions.

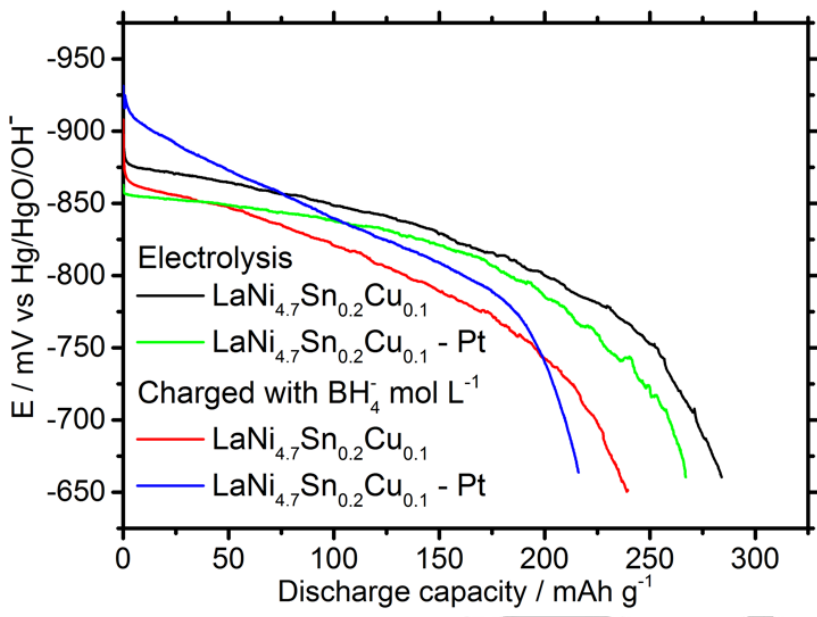

Figure 1: Electrode potential as a function of discharge capacity for $\mathrm{LaNi}_{4.7} \mathrm{Sn}_{0.2} \mathrm{Cu}_{0.1}$ with and without $\mathrm{Pt}$ when charged by the electrolysis and by exposure to $\mathrm{NaBH}_{4} 10^{-2} \mathrm{~mol} \mathrm{~L}^{-1}$ in $\mathrm{KOH} 1.0 \mathrm{~mol} \mathrm{~L}^{-1}$.

In agreement with our previously published works, ${ }^{[13,14]}$ the results of charge capacity for $\mathrm{LaNi}_{4.7} \mathrm{Sn}_{0.2} \mathrm{Cu}_{0.1}$ with and without $\mathrm{Pt}$ show that the alloys present almost the same discharge capacity when charged by both electrolysis and exposure to borohydride solution for 2 hours. For the alloy without Pt it is seen that initial potential for both methods is similar, whilst for the material with Pt charged by exposure to borohydride, the initial potential of the discharge process following chemical charging is lower (more negative) than that obtained following the electrochemical charging. This result is explained by the fact that hydrogen oxidation and the direct oxidation of borohydride ions occurred in parallel for the $\mathrm{Pt}$ modified electrode.

Fig. 2 shows the in situ XRD results obtained during the electrochemical process of charge and discharge of the $\mathrm{LaNi}_{4.7} \mathrm{Sn}_{0.2} \mathrm{Cu}_{0.1}$ alloy, with and without $\mathrm{Pt}$, in the range $19.5^{\circ} \leq$ $2 \theta \leq 24^{\circ}$. Noise in the data is attributed to the formation of bubbles during the charging process. Shifts in the background (removed) were also observed and attributed to the flowing electrolyte. Nevertheless, the quality of the XRD data obtained is excellent. Peaks associated with three different phases ${ }^{[12]}$ during the alloy hydriding and dehydriding for both samples are clearly observed in the data shown in Fig. 2. For $\mathrm{LaNi}_{4.7} \mathrm{Sn}_{0.2} \mathrm{Cu}_{0.1}$ (Fig. 2A) the first phase, $\alpha$ (the largest diffraction peak at $2 \theta=22.0^{\circ}$ ), refers to the original crystal structure of the alloy, containing only a small amount of hydride. The second phase, $\gamma$, (peak at $2 \theta=21.5^{\circ}$ ) represents formation of a new crystal structure due to the insertion of hydride, thus causing an expansion in the volume of unit cell. ${ }^{[12]}$ Finally, phase $\beta$ (peaks at $2 \theta=20.0^{\circ}$ and $20.5^{\circ}$ ) represents the crystal structure of either the fully hydrided alloy or with at least two-thirds of the total possible hydride content. Previous results have shown that the direct transition from phases $\alpha$ to $\beta$ represents an expansion along both the $c$ and a axes, corresponding to an increase of $25 \%$ in the crystal volume, ${ }^{[12]}$

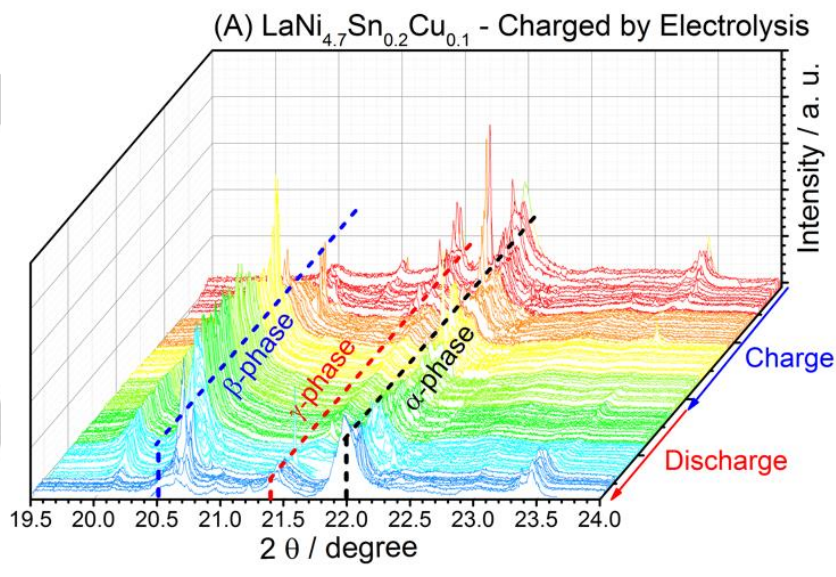

(B) $\mathrm{LaNi}_{4.7} \mathrm{Sn}_{0.2} \mathrm{Cu}_{0.1}-\mathrm{Pt}$ - Charged by Electrolysis

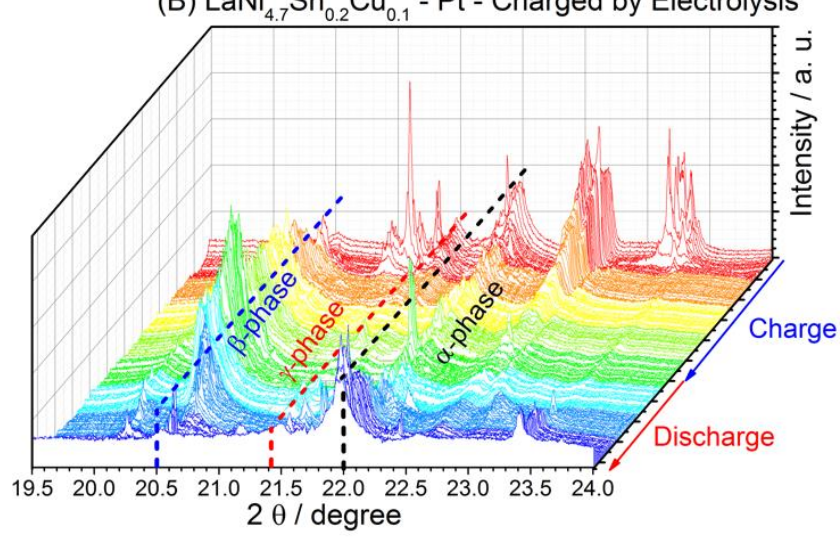

Figure 2. In situ XRD results for the $\mathrm{LaNi}_{4.7} \mathrm{Sn}_{0.2} \mathrm{Cu}_{0.1}$ alloy with and without $\mathrm{Pt}$, during the electrochemical process of charge and discharge. 
while the transition from $\alpha$ to $y$ followed by the transition from $y$ to $\beta$ result in a smaller volume expansion $(22.8 \%)$ and is thus accompanied by less localized stress. This last phenomenon is expected to occur for the alloys containing other transition metals partialy replacing $\mathrm{Ni}$ on the $\mathrm{B}$ element of $\mathrm{AB}_{5}$ metal hydride alloys, as is the case of $\mathrm{Sn}$.

The results obtained for the Pt modified alloy are shown in Fig. 2B. The peaks attributed to the $\alpha, \beta$, and $\gamma$ phases of the alloy are largely unchanged upon addition of Pt. There is, however, an additional peak characteristic of the Pt fcc lattice at $2 \theta=22.6^{\circ}$. This latter peak could only be observed due to the high intensity $x$-ray source used in these XRD experiments and was not observed in our previous studies. ${ }^{[13,14]}$

Fig. 3 shows plots of the intensity of the more prominent peaks for each phase as a function of the charging/discharging time for the $\mathrm{LaNi}_{4.7} \mathrm{Sn}_{0.2} \mathrm{Cu}_{0.1}$ and $\mathrm{LaNi}_{4.7} \mathrm{Sn}_{0.2} \mathrm{Cu}_{0.1}$ - Pt samples. In both cases the peaks for the $\alpha$ and $y$ phases decrease slightly during the charging and then increase during discharge. An opposite trend is observed for the peak attributed to the $\beta$ phase. For the alloy without $\mathrm{Pt}$, in particular, it is observed that the $\alpha$ and $\mathrm{Y}$ phases coexist in the beginning of the charge, with the $\gamma$ phase most likely being present at the surface of the metal hydride particles, while the a phase is in the core. The opposite may occur at the end of discharge, explaining why the maximum peak intensity of the $y$-phase is lower at the beginning of the alloy
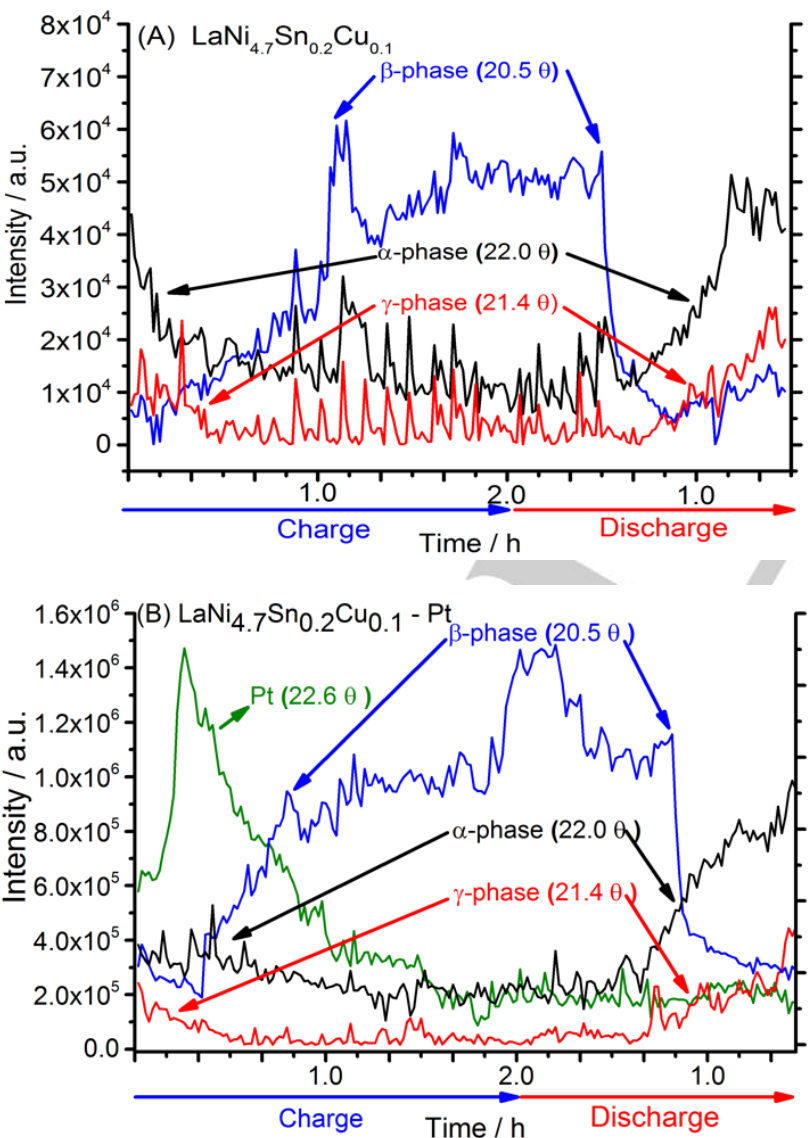

Figure 3: Peak intensity for $\mathrm{LaNi}_{4.7} \mathrm{Sn}_{0.2} \mathrm{Cu}_{0.1}$ and $\mathrm{LaNi}_{4.7} \mathrm{Sn}_{0.2} \mathrm{Cu}_{0.1}-\mathrm{Pt}$ during the charge and discharge process by electrolysis. charging than at the end of discharge, when a compression of the crystal structure occurs due to the hydride oxidation. ${ }^{[10]}$

It should be noted that the $\gamma-\beta$ phase transformation involves the transition between a phase with low concentration of hydride species to another one initially containing low hydride content, but retaining the structure up to the insertion of about two-third of the full possible $\mathrm{M}-\mathrm{H}$ content. ${ }^{\left[{ }^{5]}\right.} \mathrm{A}$ continuous lattice expansion and contraction occurs during this $\mathrm{Y}-\beta$ phase transition, ${ }^{[5]}$ as mentioned above.

Figs. 4 and 5 show the corresponding in situ XRD results for the $\mathrm{LaNi}_{4.7} \mathrm{Sn}_{0.2} \mathrm{Cu}_{0.1}$ alloy with and without $\mathrm{Pt}$, obtained during chemical charging, followed by the electrochemical discharge.

Some differences with respect to the XRD patterns obtained during the electrochemical charging are apparent. For $\mathrm{LaNi}_{4.7} \mathrm{Sn}_{0.2} \mathrm{Cu}_{0.1}$ it is observed (Fig. $4 \mathrm{~A}$ ) that the $\alpha-\gamma$ phases are apparent, but there is no significant appearance of the $\beta$-phase, as also shown in Fig. 5 . This suggests lower insertion of hydrogen into the lattice structure in this later case, compared to those of electrochemical charging. This is consistent with the results presented in Fig. 1, which indicates that the total charge accumulated during chemical charging is ca. $80 \%$ of the total charge accumulated from electrochemical charging. Regarding the lines for the $\alpha-\gamma$ phases in Fig. 5 , it should be noted that the trends are similar as those for the electrochemically

(A) $\mathrm{LaNi}_{4.7} \mathrm{Sn}_{0.2} \mathrm{Cu}_{0.1}$ - Charged by exposure to $\mathrm{BH}_{4}^{-}$for $2 \mathrm{~h}$

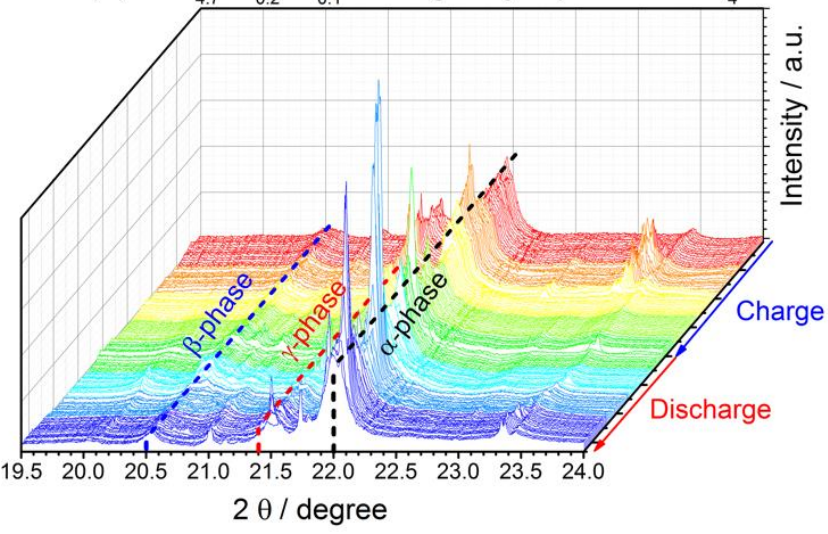

(B) $\mathrm{LaNi}_{4.7} \mathrm{Sn}_{0.2} \mathrm{Cu}_{0.1}-\mathrm{Pt}$ - Charged by exposure to $\mathrm{BH}_{4}^{-}$for $2 \mathrm{~h}$

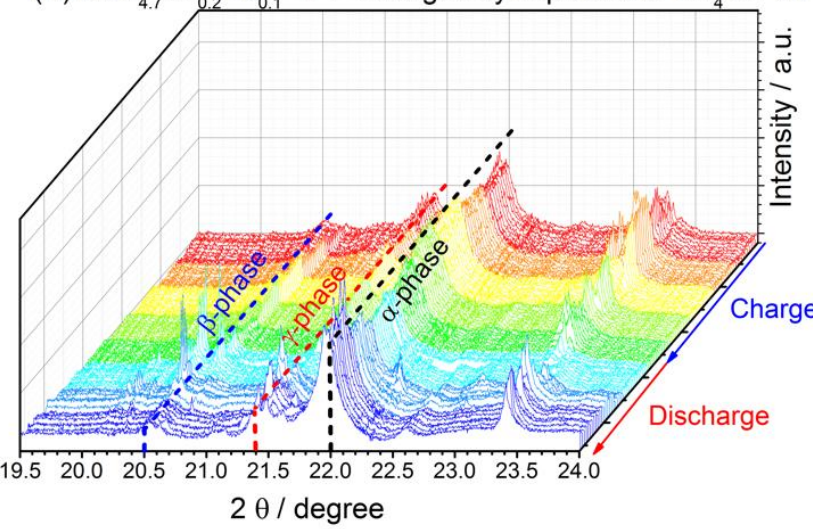

Figure 4. In situ XRD results for the alloy $\mathrm{LaNi}_{4.7} \mathrm{Sn}_{0.2} \mathrm{Cu}_{0.1}$ with and without $\mathrm{Pt}$ deposited during the charge by exposure of $\mathrm{BH}_{4}{ }^{-} 10^{-2} \mathrm{M}$ for $2 \mathrm{~h}$ followed by the electrochemical discharge. 


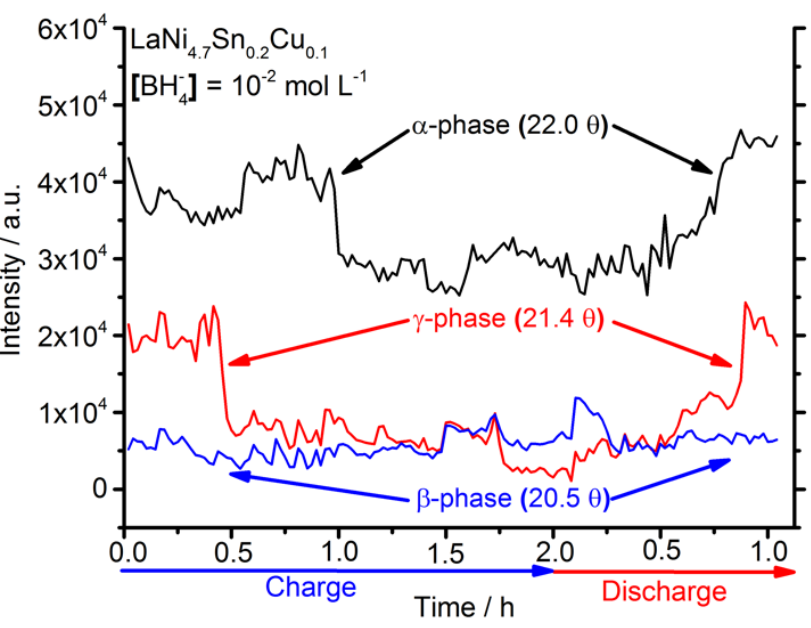

Figure 5: Peak intensity for $\mathrm{LaNi}_{4.7} \mathrm{Sn}_{0.2} \mathrm{Cu}_{0.1}$ during the charge by exposure to borohydride $10^{-2} \mathrm{~mol} \mathrm{~L}^{-1}$ and discharged by electrolysis.

charged/discharged alloys (Fig. 3). So, these results are consistent with the fact that, as mentioned before, the $y$ phase is present at the surface of the metal hydride particles, while the $a$ phase is in the core. The results for the alloy with Pt show that, also in this case the charging and discharging only involves the $\alpha$ Y phase transition.

As mentioned before, the $\beta$-phase appears for levels of alloy hydriding higher than ca. $67 \%$, meaning that the appearance of this phase would only occur by the end of the alloy chemical charging and the beginning of the discharging, but this is not confirmed. Explanation for this contradiction may be given in terms of the presence of residual borohydride covering the metal hydride particle surface or trapped into the carbon network support following the chemical charging, which may be able to replenish some of the oxidized hydride in the course of the discharging process. As mentioned above for the Pt-containing alloy, the lower potentials observed in the beginning of the discharge step provide evidence of the presence of the borohydride ions in contact with the Pt particles, because of the lower reversible potential of the borohydride oxidation compared to that of the metal hydride.

In summary, the appearance of the $Y$-phase during the borohydride charging process confirms hydride insertion into the alloy. However, there is no formation of the $\beta$-phase and this indicate occurrence of smaller localized stress in the alloy, compared to the electrochemical charging, with benefit on the alloy lifetime, as evidenced by the results in Fig. S2 (support information). So, results show that the system essentially remains with the $\alpha$ and $y$-phases during the whole experiments, confirming that the charging process by exposure to borohydride is in fact smaller than the electrochemical step, but this is not surprising because of the low $\mathrm{BH}_{4}$ - concentration used in the chemical charging process.

\section{Conclusions}

The in situ XRD results have shown that the method of charging of the alloy, electrochemical or chemical, leads to different phase predominance and different site occupancies, but both methods lead to almost the same discharge capacity. In the electrolysis process, the $\gamma-\beta$ phase transition is predominant while in the chemical charging by the exposure to borohydride solution the $\alpha$ $\mathrm{Y}$ phase transition is more important, indicating occurrence of smaller localized stress in the alloy, with benefit on the material lifetime. The results have also shown that the alloys with and without Pt lead essentially to the same phenomena, either with respect to the alloy structure and the electrochemical characteristics.

\section{Acknowledgements}

The authors would like to thank the São Paulo Research Foundation - Fapesp (Process numbers: 2012/21835-0, 2012/09109-12, and 2013/16930-7) Brazil and the Diamond Light Source (Beamline I11), United Kingdom.

Keywords: In situ XRD • Flow cell • Borohydride oxidation reaction $\cdot$ Hydrogen storage alloys.

[1] B. Choi, C. Lee, and A. Tsutsumi, Journal of Power Sources 2009 194, 1150-1155.

[2] L. Wang, C. Ma, Y. Sun and S. Suda, Journal of Alloys and Compounds 2005, 391, 318-322.

[3] J. Ma, A. Choudhury and Y. Sahai, Renewable and Sustainable Energy Reviews, 2010, 14, 183-190.

[4] M. Sato, M. Stange and V. A. Yartys, Journal of Alloys and Compounds 2005, 396, 197-201.

[5] D. Chartouni and K. Gross, K, Journal of Electrochemical Society 2001, 148, A241-248.

[6] K. Young, B. Chao, B. Hunag and J. Nei, Journal of Alloys and Compounds 2014, 588, 235-241.

[7] S. Yang, S. Han, J. Song and Y. Li, Journal of Rare Earths 2011, 29, 692.

[8] D. Zhang, G. Wang, K. Cheng, J. Huang, P. Yan and D. Cao, Journal of Power Sources 2014, 245, 482-486.

[9] P. Norby, Journal of American of Chemical Society 1997, 119, 52155221.

[10] M. Stange, J. P. Maehlen, V. A. Yartys, P. Norby, P., W. Van Beek and H. Emerich, Journal of Alloys and Compounds 2005, 404, 604608.

[11] Y. Nakamura, R. Bowman and E. Akiba, Journal of Alloys and Compounds 2004, 373, 183-193.

[12] Y. Nakamura and E. Akiba, Journal of Alloys and Compounds 2000 308, 309-318.

[13] W. J. Paschoalino, S. J. Thompson, A. E. Russell and E. A. Ticianelli, ChemPhysChem 2014, 15, 2170-2176.

[14] W. J. Paschoalino and E. A. Ticianelli, International Journal of Hydrogen Energy 2013, 38, 7344-7352. 


\section{FULL PAPER}

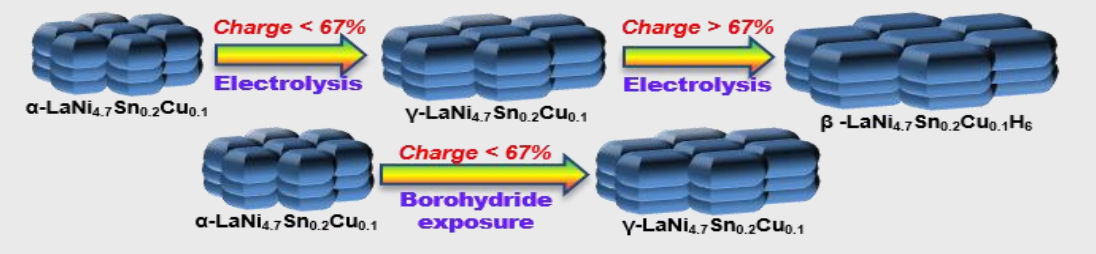

In situ X-ray diffraction XRD was used to investigate the phase transitions of the metal hydride alloys when the electrodes were charged/discharged. Results have shown that the method of charging, electrochemically or chemically, leads to different phase predominance and different site occupancies, but both methods lead to almost the same discharge capacity.
Waldemir J. Paschoalino, Dr. Stephen J. Thompson, David Inwood, Dr. Claire Murray, Dr. Chiu C. Tang, Prof. Edson A. Ticianelli(*) and Prof. Andrea E. Russell.

Page No. - Page No.

In situ X Ray Diffraction Investigation of Hydrogen Storage Alloys During Charge and Discharge 